\title{
A Facile Preparation of Silver Nanocolloids by Hydrogen Reduction of a Silver Alkylcarbamate Complex
}

\author{
Hyun-Ki Hong, Myoung-Seon Gong, and Chan-Kyo Park ${ }^{* *}$ \\ Department of Nanobiomedical Science, Dankook University, Chnngnam 330-714, Korea \\ ${ }^{\dagger}$ Department of Applied Chemical Engineering. Dankook Lniversitw, Chungnam 330-714, Korea \\ E-mail: chanparkáalankook.ac.kr \\ Received August 11, 2009. Accepted September 25, 2009
}

\begin{abstract}
Controlled reduction of silver alkylcarbanate complexes with hydrogen gas was investigated as a facile synthetic method for high concentrations of silver nanocolloids in organic solvent. Polyvinylpy rolidone (PVP) was used to stabilize the silver colloids obtained from the chemical reduction. To determine optimum conditions for preparation of the stable and controlled silver colloids with the narrowest particle size and distribution, a large number of experiments were carried out involving variations in the concentrations of the silver 2 -ethylhery lcarbamate (Ag-EHCB) complex, PVP, and 2-propanol. The initial colloid had a mean particle diameter between $5 \sim 50 \mathrm{~nm}$ as measured by transmission electron microscopy, and exhibited a shapp absorption band in the UV region with a maximum size near $420 \mathrm{~nm}$. After treatment with a reducing agent, the colloids were characterized by ultraviolet-visible spectroscopy, X-ray diffraction, and high-resolution transmission electron microscopy.
\end{abstract}

Key Words: Silver nanocolloid. Silver alky'lcarbamate. Reduction. Hydrogen. Organic solvent

\section{Introduction}

A variety of methods can be employed for the formation of silver nanoparticles. including electrolysis. ${ }^{1}$ biochemical. ${ }^{\text {" }}$ gas condensation ${ }^{3}$ laser ablation of a silver metal plate, ${ }^{4}$ laser irradiation of an aqueous silver solution. ${ }^{5}$ sol-gel techniques. ${ }^{6}$ sonochemical deposition." nanostructured templates. ${ }^{8}$ and thermal decomposition. ${ }^{9}$ Generally. silver nanoparticles are synthesized by the reduction of silver salts in the presence of organic stabilizers in a manner similar to the acclaimed Brust's method for the synthesis of gold nanoparticles. ${ }^{10}$ The reduction of $\mathrm{Ag}(\mathrm{I})$ salt to metallic Ag( 0 is carried out by strong reductants such as sodium borohydride. ${ }^{11,12}$ sodium citrate. ${ }^{11.13}$ hydrogen gas. ${ }^{14}$ ascorbic acid. ${ }^{15.16}$ DMSO. ${ }^{15}$ hy'drazine dillydrochloride ${ }^{13.15}$ potassium bitartate, ${ }^{\text {(1) }}$ ethanol, py ridine. DMF, ${ }^{21}$ and poly (ethylene glycol) ${ }^{\text {"2 }}$ However these reactions have exhibited difficulties in application towards large-scale synthesis in organic solvents owing to their highly diluted and exothermic conditions.

Several silver salt precursors have been employed in the synthesis of silver nanoparticles. Silver nitrate $\left(\mathrm{AgNO}_{3}\right)^{11.18,73,24}$ is the most common source of silver ions. although $\mathrm{Ag}_{2} \mathrm{SO}_{4}{ }_{4}{ }^{11}$ silver 2-ethy lhexonate. ${ }^{17}$ silver oxide, ${ }^{15}$ and silver perchlorate ${ }^{35}$ have also been used. Generally, the actual size of the nanoparticles obtained varies from system to system, not only because the stabilizer, the reducing agent. and the nature of the metal are varied. but also due to parametrical differences in solvent. concentration. temperature, and reduction time.

Silver organic salts have been used to produce silver nanoparticles and conductive silver tracks. In these processes. silver carboxylate ${ }^{26.310}$ or silver alky'lcarbamate complexes ${ }^{31.36}$ are reduced to silver metal by heating and reduction with hydrazine. However, no other reports have described the formation of silver nanocolloid wia the one-pot reduction of silver alky'carbamate complex in organic solution using hydrogen gas as the reducing agent. This method offers the advantages of being able to produce the essentially clean silver particles. which contains no inorganic ions except anine and carbon dioxide. even at room temperature

The present work examines the preparation of silver nanoparticles through a simple hydrogen reduction process using a silver 2-ethylhexy lcarbamate (Ag-EHCB) complex in 2-propanol. The reduction of Ag-EHCB under a hydrogen atmosphere was sy stematically carried out in order to investigate the effects upon size and morphological characteristics of the silver particles. The experimental conditions. including amount of solvent. concentration of Ag-EHCB and stabilizer for preparation of the silver nanoparticles. and reduction mechanism, were also inferred.

\section{Experimental Section}

Chemicals and measurements. The silver 2-ethylhexylcarbamate (Ag-EHCB) complex solution (silver content. 10\%) was purchased from Inktec Co. Ltd (Ansan, South Korea). The 2-propanol (Ducksan Chem. Co. Ansan. South Korea) was used as received. The PVP (Aldrich Chem. Co.), molecular weight of 40,000 . was used to stabilize the silver colloidal suspensions.

Neither high aspect ratio particles nor any aggregated clusters were removed by gravity-filtration through a membrane filter or centrifugation to concentrate the silver nanoparticle suspension. The TEM observations were carried out using a JEOL electron microscope (JEM-2000EXII). Prior to measurement, the samples were prepared by dropping a sinall anюunt of the diluted silver colloid solution to a carbon-coated copper grid. After the solvent evaporated. the particles were sized.

Silver nanocolloid solutions were diluted in 2-propanol and then placed in a quartz cuvette ( $1 \mathrm{~cm}$ path length) with the incident light beam perpendicular to the radial direction of the sam- 
Table 1. Conditions for the preparation of silver particles using silver alkylcarbamate complex solution by reduction with hydrogen gas.

\begin{tabular}{|c|c|c|c|c|c|c|}
\hline Samples (No.) & $\operatorname{PVP}^{a i}(\mathrm{~g})$ & Solvent $(\mathrm{mL})$ & $A g-\mathrm{EHCB}^{c}(\mathrm{~g})$ & {$[\mathrm{PVP}] /[\mathrm{Ag}]^{d l}$} & {$[\mathrm{Ag}-\mathrm{EHCB}] \times 10^{3}(\mathrm{~mol} / \mathrm{L})$} & {$[\mathrm{PVP}] \times 10^{3}(\mathrm{~mol} / \mathrm{L})$} \\
\hline 1 & 1 & 20 & 0.05 & 3.8835 & 2.3178 & 9.0 \\
\hline 2 & 1 & 20 & 0.1 & 0.9410 & 4.6365 & 9.0 \\
\hline 3 & l & 20 & 0.2 & 0.9708 & 9.2713 & 9.0 \\
\hline 4 & 1 & 20 & 0.3 & 0.6470 & 13.9100 & 9.0 \\
\hline 5 & 1 & 20 & 0.4 & 0.4854 & 18.5430 & 9.0 \\
\hline 6 & l & 20 & 0.5 & 0.3882 & 23.1831 & 9.0 \\
\hline 7 & 1 & 10 & 0.1 & 1.9410 & 9.2713 & 9.0 \\
\hline 8 & 1 & 30 & 0.1 & 1.9410 & 3.0910 & 9.0 \\
\hline 9 & 1 & 40 & 0.1 & 1.9410 & 2.3178 & 9.0 \\
\hline 10 & 0.5 & 20 & 0.1 & 0.9706 & 4.6365 & 4.5 \\
\hline 11 & 2 & 20 & 0.1 & 3.8835 & 4.6365 & 18.0 \\
\hline 12 & 3 & 20 & 0.1 & 5.8241 & 4.6365 & 27.0 \\
\hline 13 & 4 & 20 & 0.1 & 7.7640 & 4.6365 & 36.0 \\
\hline 14 & 5 & 20 & 0.1 & 9.7087 & 4.6365 & 45.0 \\
\hline 15 & 5 & 20 & 0.7 & 1.3866 & 32.4560 & 45.0 \\
\hline 16 & 5 & 20 & 0.9 & 1.0784 & 41.7290 & 45.0 \\
\hline 17 & 5 & 20 & 10 & 0.9706 & 46.3650 & 45.0 \\
\hline 18 & 5 & 20 & 1.5 & 0.6470 & 69.5480 & 45.0 \\
\hline
\end{tabular}

${ }^{a}$ Polytinylpyrrolidone $\left(1 \mathrm{~g} .9 .0 \quad 10^{-2}\right.$ mol L): ${ }^{k} 2$-Propanol: 'Silver 2-ethyllexylcarbanate: ${ }^{d}$ The ratio of [PVP] to [Ag-EHCB].

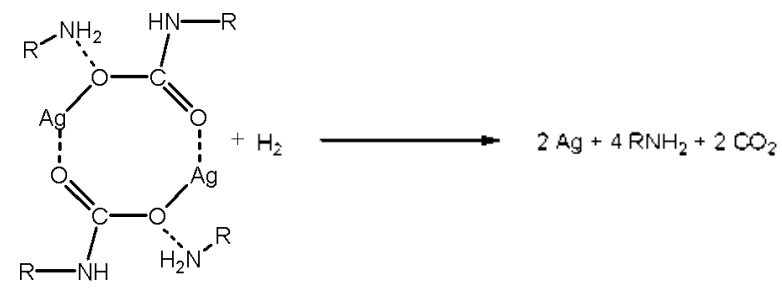

Scheme 1

ple. The UV-Vis spectra were obtained using the Shimadzu. UV$160 \mathrm{lPC}$ spectrometer over a 200 to $800 \mathrm{~nm}$ range with $1 \mathrm{num}$ resolution and background correction using 2-propanol. The XRD patterns of the Ag nanoparticle were measured using a Shimadzu XD-D1 X-ray diffractometer with $\mathrm{CuK}_{\text {, }}$ radiation $(\hat{\partial}=1.54056 \AA)$ at a scanning rate of 2 degrees per second in $2 \theta$ ranging from $30^{\circ}$ to $90^{\circ}$. The XRD sample was supported on glass substrates.

Preparation of silvernanocolloid solution. The vessel used for particle synthesis was a $500 \mathrm{~mL}$. stainless steel pressure reactor equipped with a gas regulator and gas inlet and outlet șistem. The PVP ( $1.0 \mathrm{~g}$ ) and silver 2-ethylhexylcarbamate complex $(0.10 \mathrm{~g})$ were first dissolved in anhydrous 2-propanol (20.0 g) in the pressure reactor $(500 \mathrm{~mL})$. After the reactor was degassed with a vacuum pump. hydrogen gas was pressurized up to 4.5 atm at $25^{\circ} \mathrm{C}$. The solution was then stirred for $2 \mathrm{~h}$ to give the silver nanocolloid solution. Other silver nanocolloid solutions with varying PVP content. solvent. and silver carbamate complexes were prepared by similar procedures as described above.

\section{Results and Discussion}

Preparation of silvercolloidal solution. Silver nanoparticles can be synthesized by the reduction of a silver 2-ethylhexylcarbamate (Ag-EHCB) complex in an organic solvent under a pressurized hydrogen gas atmosphere. Simple charge of the gas over the stirred Ag-EHCB complex solution in 2-propanol at room temperature resulted in formation of a silver colloidal suspension at high concentration. When a solution of the silver carbamate complex reacted with hydrogen, the precursor solution gave the silver metal. carbon dioxide, and a corresponding primary amine as shown in Scheme l. Because hydrogen and silver alkylcarbantate are the only components used in the reduction. no other inorganic chemical. except an organic anine and carbon dioxide. is present in the final colloidal solution.

This procedure was very efficient and provided the required experimental control for the synthesis of well-defined nanoparticles. Because hydrogen and silver alkylcarbanate were the only components used in the reduction, no other inorganic chemicals were present in the final colloidal solution.

For the dispersion of the produced silver nanoparticles in solution. PVP was employed as the stabilizer. The silver alkylcarbantate complex, in 2-propanol and in the presence of the PVP stabilizer, did not change the color of the solution at the experimental temperature. This result suggested that PVP itself does not reduce the silver alkylcarbamate complex. When hydrogen gas was introduced into the Ag-EHCB complex solution. the solution color changed to a deep brown. At this time, the precursor was rapidly reduced to produce the silver nanoparticles.

To determine the optinum conditions for preparation of stable silver colloids with the narrowest particle size distribution. a large number of experiments were carried out. varying the concentration of Ag-EHCB conplex. PVP, and 2-propanol in the reaction mixture. Table 1 .

Effect of the concentration of Ag-EHCB. Figure l shows a group of UV-Vis absorption spectra for the colloidal solution obtained from $4.6365 \times 10^{-3}$ to $2.3283 \times 10^{-2} \mathrm{~mol} / \mathrm{L}$ of Ag-EHCB complex at the same hydrogen pressure. The complete reduction of the silver colloids could be monitored by UV-Vis spectroscopy. specifically by the appearance of the absorption bands of the 


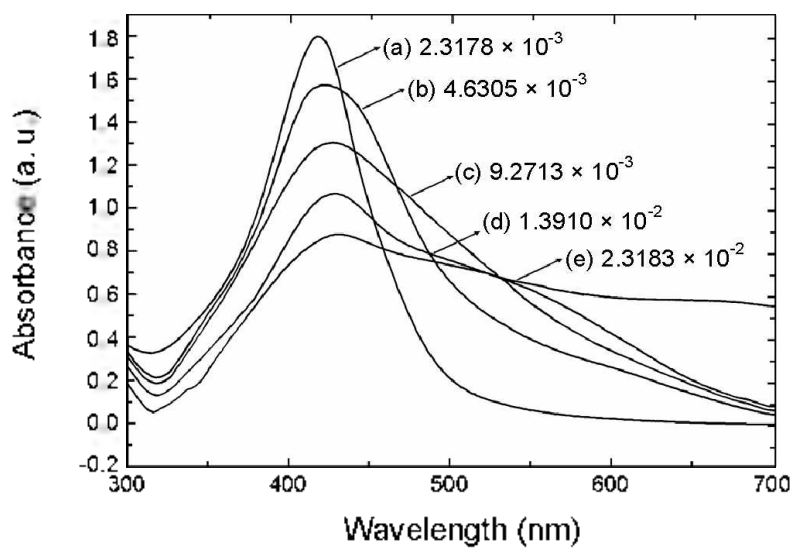

Figune 1. lIV-Vis spectra of silver colloidal solutions w ith different concentration $(\mathrm{mol} / \mathrm{L}$ ) of $\mathrm{Ag}-\mathrm{l}$ : I ICI3.

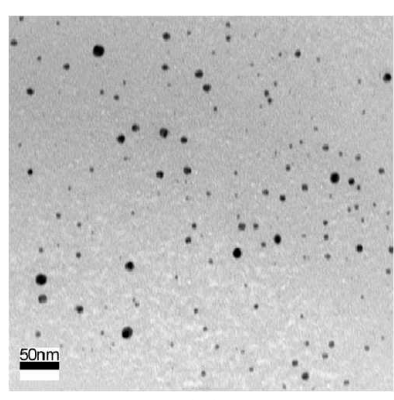

(a)

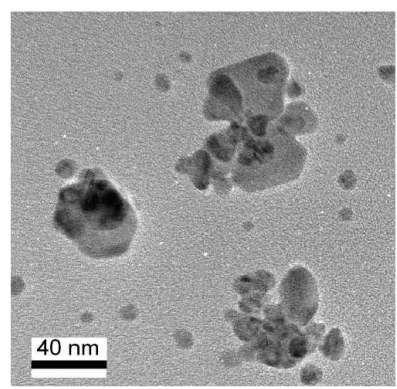

(c)

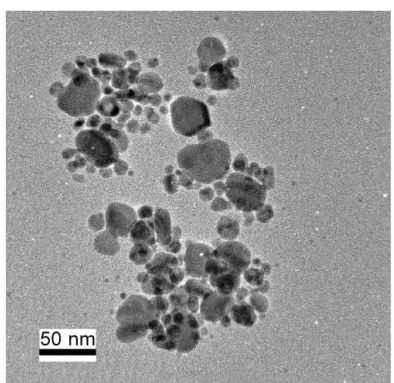

(c)

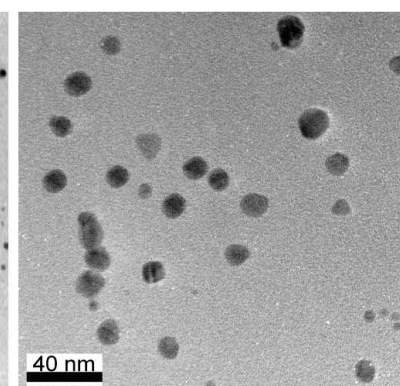

(b)

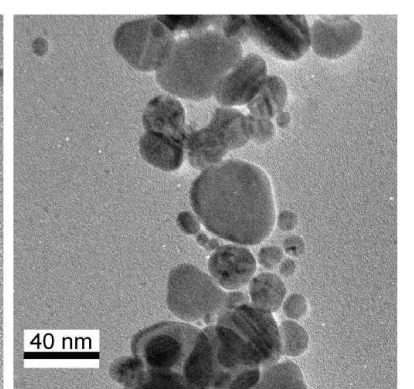

(d)

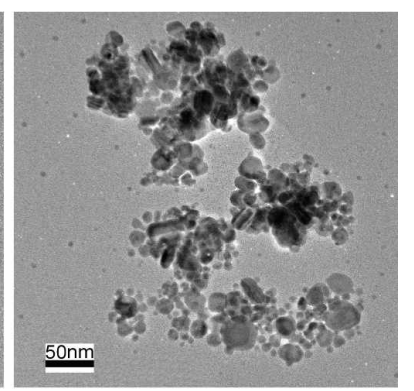

(f)
Figure 2. "THM image of dillerent sire and shape of silver nanesperticle st nthesized w hydrogen reduetion of silyor alkvleashan ate comples at a concentration of (a) $2.3178 \times 10^{-3}$ (b) $4.6365 \times 10^{-2}$ (c) $9.2713 \mathrm{~K}$ $10^{-3}:$ (d) $1.3910 \times 10^{-2}$, (c) $1.8543 \times 10^{-2}$ and (1) $2.183 \times 10^{-2} \mathrm{~mol} / \mathrm{L}$.

silver surface plasmon near $420 \mathrm{~nm}$. Because the concentration of Ag-EHCB reached at least $2.3178 \times 10^{-3} \mathrm{~mol} / \mathrm{L}$, the maximum UV absorption spectra of the resulting plasmon peak of the silver nanoparticles did not shift below $420 \mathrm{~nm}$. Apparent changes

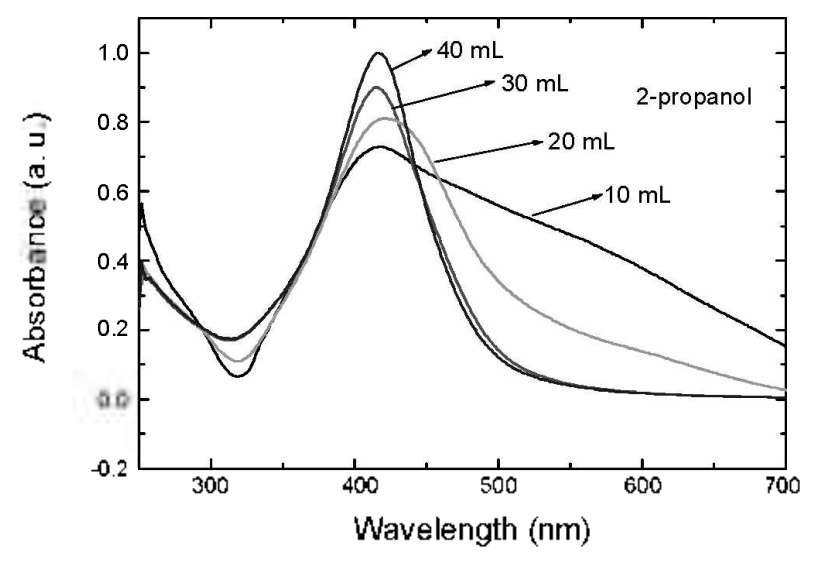

ligure 3. l V V-Vis ahsoption spectra of silver collojedal wolutions ohtained from various amounts ol 2 -propanol solvent with $9.0 \times 10^{-3}$ mel/I, of $\mathrm{P}^{\mathrm{V}} \mathrm{l}$ 'sabilizar.

in absorbance were detected during the wo hours under the hy drogen atmosphere at room temperature. Room temperature synthesis of silver nanoparticles was monitored by recording the changes in the UV-Vis spectra over time for different concentrations of the Ag-EHCB complex. At lower Ag-EHCB concentrations. the absorption band was narrowed and shifted continuously to shorter wavelengths as shown in Figure $\mathrm{l}(\mathrm{a})$ and $\mathrm{l}(\mathrm{b})$. In the case of relatively high concentrations of Ag-EHCB (1.8543 * $10^{-2}$ and $\left.2.3175 \times 10^{-2} \mathrm{~mol} / \mathrm{L}\right)$. a ver broad and ast mmetric absorbance band was obsered. Figure I(d) and I(c). Upon increasing the concentration of the Ag-EHCB complex, the band showed a red shift in the maximum of the plasmon peak. 'l'hese features were associated with the size and distribution of the ș nthesized silver nanoparticles.

The TEM images of the nanoparticles obtained from six diflerent suspensions are shown in Figure 2. The smallest size $(5 \cdots 20 \mathrm{~nm})$ shown in Figure 2(a) is from the suspension obtained at a lower Ag-EHCB concentration. $2.3178 \times 10^{-3}$ and $4.6365 \times 10^{-3} \mathrm{~mol} / \mathrm{L}$, while the largest $(10 \cdots 80 \mathrm{~mm})$ corresponds to higher concentrations obtained from those in experiment No. 3-6 $\left(|\mathrm{Ag}-\mathrm{EHCB}|=9.2713 \times 10^{-3} \cdots 2.3183 \times 10^{-2} \mathrm{~mol} / \mathrm{L}\right)$. At higher concentrations of Ag-EHCB, the particles were especially. multi-dispersing with concomitant aggregation of the particles. At Ag-EHCB concentrations greater than $9.2713 \times 10^{-3} \mathrm{~mol} / \mathrm{L}$. agglomerated particles of $\backslash$ arious sizes and shapes formed en masse. as shown in Fig 2(c)-2(c). In comparison. smaller particles accompanied the agglomerations from Exp No. 3-6, and larger particles without agglomeration lor Exp. No. 1 and 2. Most nanoparticles were well-dispersed and sphere-shaped. coinciding with the abovementioned speculation of the UV-Vis absorption spectra.

As a result, a wide distribution of particle sizes have been a distinguishing feature of silver colloids prepared by reduction of silver alkyl carbamate complexes with hydrogen. A yaricty of shapes from spheres to cubes. and from triangles to hexagons, with lengths of $5,50 \mathrm{~nm}$ and even $80 \mathrm{~nm}$. have been observed in such colloids. These facts are probably due to the inhomogeneity letween the Ag-EHCB solution and hydrogen gas in the reaction mixture. 


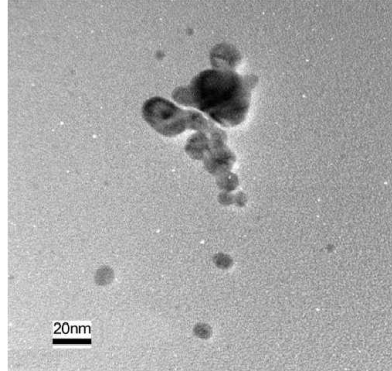

(a)

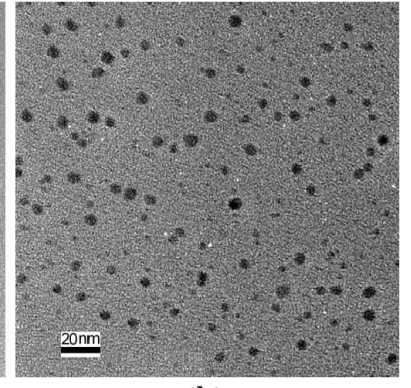

(b)

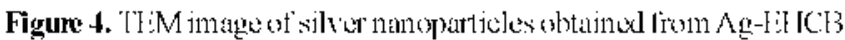
al a dillerent amount of 2-propanol solvent: $\Lambda$ getil l C C 3/2-propanol = (a) $0.1 \mathrm{~g} / 10 \mathrm{ml}$, and (b) $0.1 \mathrm{~g} / 40 \mathrm{ml}$.

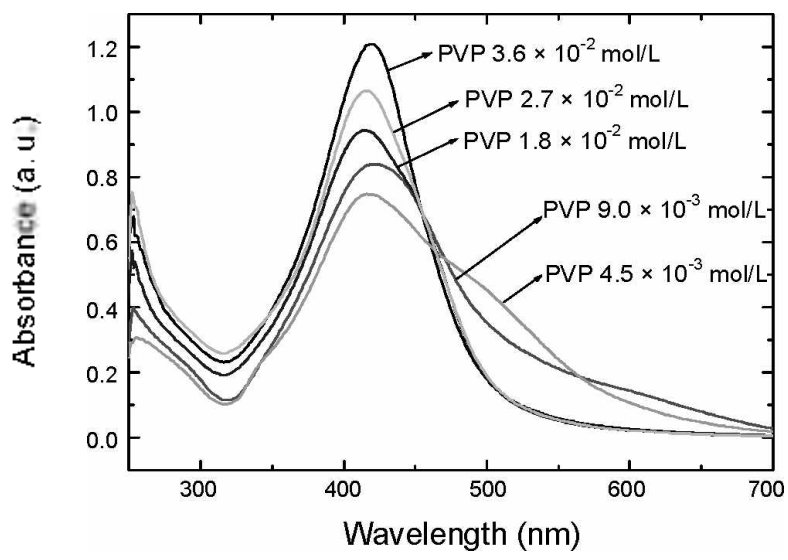

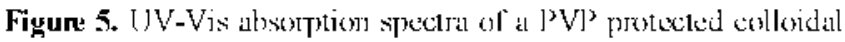
solutions:

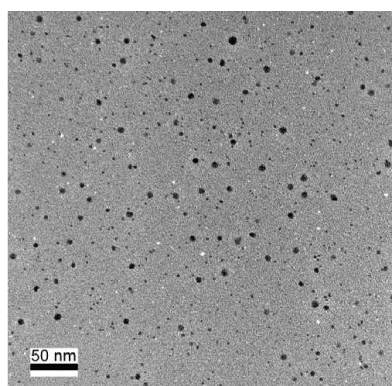

(a)

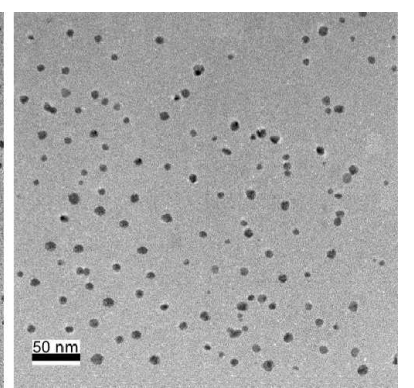

(b)
Figune 6. 'li:M image for the as prepared silver nanoparticles sinthesired by hydrogen reduction at a concentration of PVP (a) $2.7 \times$ $10^{-2}$ and (b) $3.6 \times 10^{-2} \mathrm{~mol} / \mathrm{i}$.

Effect of amount of 2-propanol solvent. An cxcess of solvent was added to cusure metal atom solvation. Stability turned out to be strongly related with solyent concentration, as with 2-propanol. 'The nore diluted the colloid in 2-propanol. the higher the expected stability. When the amount of 2-propanol was altered. the peak shape and position of the UV absorption spectrum also changed gradually. as shown in Figure 3.

Figure 4 show $\mathrm{TEM}$ micrographs of relatively monodispersed silyer particles obtained under different experimental conditions. The final particle sire depended on the amount of 2-propanol in the reaction mixture. At higher solvent contents, the primary particles experienced a sufficiently large solvation. which. in combination with the effects of the protected PVP polymer layer. may potentially prevent signilicant aggregation. Dark brown colloidal silver dispersions were obtained exhibiting average diameters near 10 or $20 \mathrm{~nm}$. The differences in si $/$ are attributed mainly to the rarying levels of 2-propanol. In the presence of excess 2 -propanol, the grow th of stabilized particles ended at a critical size of $5-10 \mathrm{~nm}$, while the poorly stabilized develop to form larger particles $(10-30 \mathrm{~nm})$ and further agglomerate, figure 4(a) and 4(b). At lower 2-propanol concentrations, the insufficiency of solyation leads to the vigorous agglomeration and irreversible flocculation observed in Figure 4 (a).

Effect of the concentration of PVP. Figure 5 shows the UV$V$ is spectra of silver colloidal solutions under different concentrations of PVP. It can be seen that with an increase in PVP concentration. the full widtl at the half maxinum absorption band due to the silver nanoparticles decreased from 107 to 85 $\mathrm{nm}$, indicating that the particle size distribution became narrower and the colloid system changed from poly dispersion to monodispersion upon increase in the concentration of PVP. Note that the strongest intensity and narrowest particle size distribution can be oblained at a minimum concentration of $9.0 \times 10^{-3} \mathrm{~mol} / \mathrm{L}$ PVP. a very low |PVP|/Ag| valuc of 0.9410 due to the existence of regenerated 2-ethy lhexylamine during reduction with hydrogen.

When the amount of the stabilizer was insufficient, it could not form a complete protection layer, thus the particles agglomerated casily to form large silver particles. Upon addition of more dispersers, it quickly formed a better-suited layer, protecting the particles from agglomeration and growth. as shown in Exp. No. $10\left(|\mathrm{PVP}|=4.5 \times 10^{-3} \mathrm{~mol} / \mathrm{L}\right)$. Moreoser, upon increasing the ratio of $|\mathrm{PVP} / \mathrm{Ag}-\mathrm{EHCB}|$ from 1.9410 to 9.7087 , the band grew more symmetrical and a blue shift in the maximum of plasmon peak appeared. These features were associated with the small and uniform size distribution of the synthesized silver nanoparticles.

For nanoparticles prepared in the presence of a stabilizer. TEM was used for the measurement of nanoparticle size and shape. A typical TEM image for the solution containing a PVP concentration of $2.7 \times 10^{-2}$ and $3.6 \times 10^{-2} \mathrm{~mol} / \mathrm{L}$ PVP is shown in Figure 6.

Well-stabilized particles with a critical size near $5 \cdots 10 \mathrm{~nm}$ formed predominantly under the protection of PVP. Even at higher Ag-EHCB concentrations, the strength of the stabilization was such that less agglomeration occurred and a lower standard deviation was obtained, Figure 6. As for a PVP concentration of $4.5 \times 10^{-2} \mathrm{~mol} / \mathrm{L}$, well-stabilized and small particles of $4 \cdots 5 \mathrm{~mm}$ without agglomeration, resulted. Sufficiently high Ag-EHCB concentrations ( 15 -fold), however, cannot effectively protect the Ag particles so that multidistribution appeared and agglomeration occurred. Figure 7(a)-(c). The arerage particle size increased with increasing Ag-EHCB concentration. coinciding with the interference from the plasmon absorption spectra.

Stability of silver nanoparticles. To monitor the stability of the final produced silver colloid, the change in time for the absorption spectra of the colloid on different days was measured. There was no obvious change in the shapc. position. or ass mmetry of the absorption peak during the initial 30 days. The reduction by 


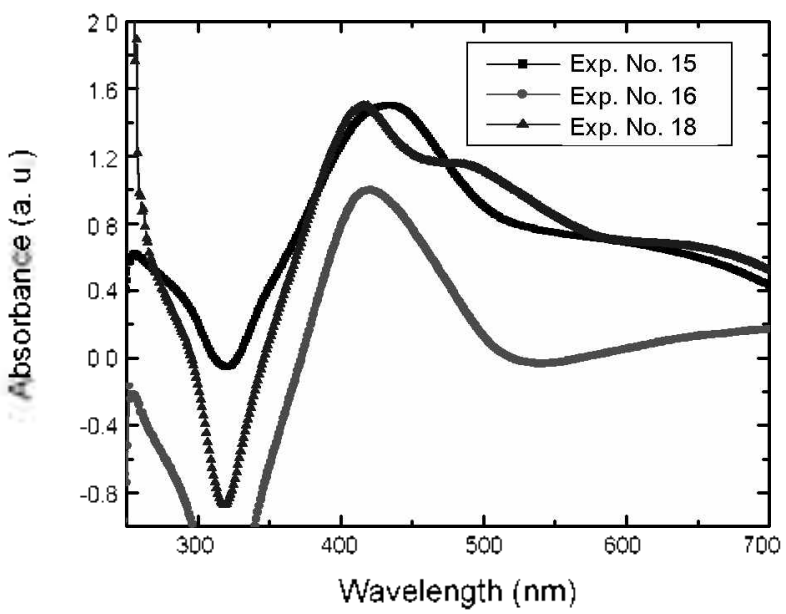

Figure 7. UV-Vis absorption spectra of silver colloidal solutions obtained from various amounts of Ag-EHCB and PVP (a) Exp. No. 15. (b) Exp. No. 16 and (c) Exp. No. 18

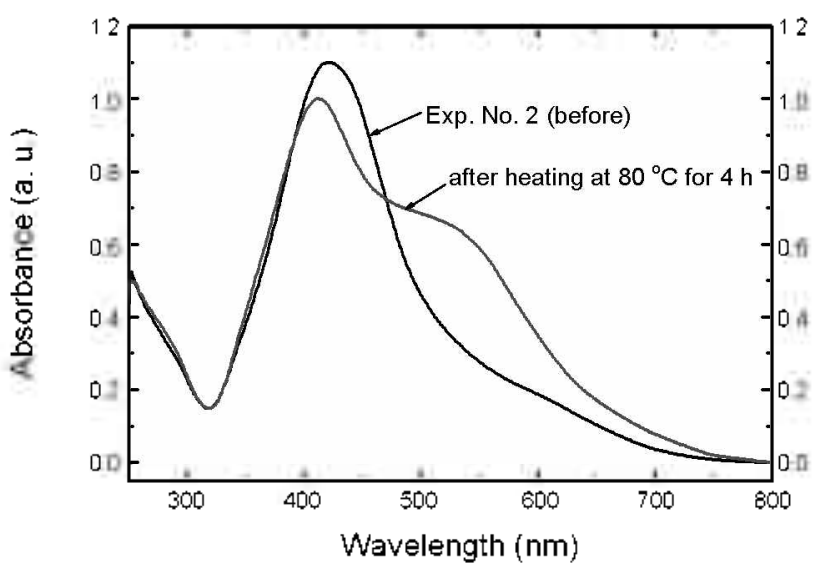

Figure 8. UV-Vis absontion spectra of silver colloidal solutions obtained from colloidal solution a) before and b) after heating for 4 hr at $80^{\circ} \mathrm{C}$

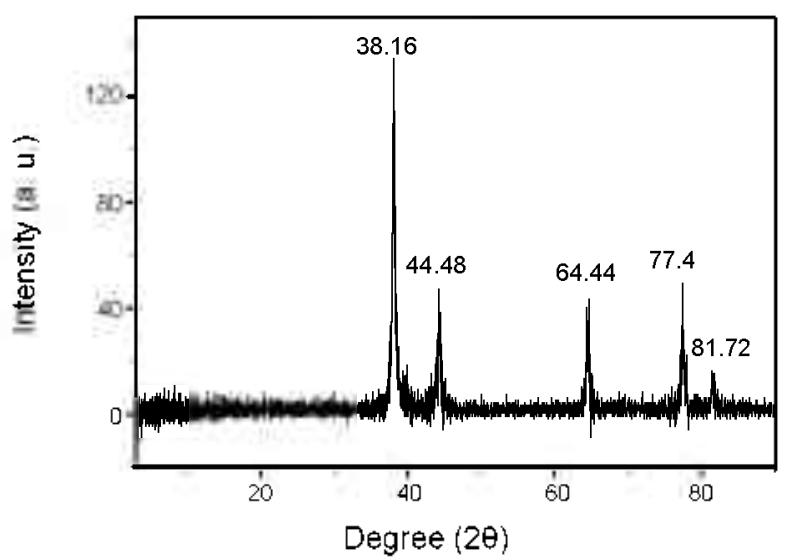

Figure 9. Powder X-ray diffraction pattern of a silver nanoparticle obtained from silver colloid solution (Exp. No. 15).

hydrogen resulted in very stable samples without precipitation occurring after 30 days or months. When the colloidal solution from Exp. No. 2 was heated at $80^{\circ} \mathrm{C}$ for $24 \mathrm{~h}$. the full width of highest maxima (fwhm) of the spectrum grew wider than before, and the peak maximum and shape showed a red slift with asy mmetry. implying the onset of nanoparticle aggregation.

Characterization. The nanoparticles synthesized by hydrogen reduction were characterized with XRD. The XRD patten of the silver nanoparticles with a diameter $5 \sim 50 \mathrm{~nm}$ obtained from a 2-propanol solution suspension at a concentration of $2.183 \times$ $10^{-2}$ mol/L is shown in Figure 9. The pattem exhibits peaks at $2 \theta$ angles of $38.16,44.48 .64 .44,77.40$, and 81.72 that correspond to the (111), (200), (220), (311), and (222) crystal planes of silver, respectively.

\section{Conclusion}

In conclusion colloidal silver particles in the nanosize range were prepared in 2-propanol by the reduction of silver 2-ethy lhexylcarbamate complex with ly drogen. The main mechanism is the hydrogen reduction of the silver carbamate complex to the neutral state of silver by hydrogen. Furthernnore. we can point out that the use of a silver alky lcarbamate complex solution on silver/PVP dispersions can be employed to obtain silver dispersions in organic solvents such as 2-propanol, a method unique from others described in the literature. As such. a facile method for the preparation of silver nanocolloid dispersions containing no inorganic ions was developed using a silver carbamate complex.

Acknowledgments. The present research was conducted by the research fund of Dankook University in 2009.

\section{References}

1. Rodniguez-Sanchez, L.; Blanco, M. C.; Lopez-Quintela, M. A.J. Phys. Chent B 2000, 10t, 9683.

2. Mukherjee, P.; Alunad, A:- Mandal, D.; Senapati, S.; Sainkar, S. R.: Khan, M. I.: Parishcha, R.; Ajaykumar, P. V.: Alam, M.: Kumar, R.; Sastry, M. Nano Lett. 2001, 1, 515

3. Hayashi, T.: Ohno, T.: Yatsuya, S.: Uyeda, R. Jpn. J. Appl.Phus. $977,16,705$.

4. Mafune, F.; Koluno, J; Takeda, Y,; Kondow, T. J.Phys. Chem. B $2000,104,8333$

5. Abid, I. P.: Wark, A. W.; Brevet, P. F.; Girault, H. H. Chem. Commun. 2002. 792

6. Brugger, P. A.; Guendet, P: Gratzel, M. J. Ant. Chem. Soc. 1981 , $103,2923$.

7. Pol, V. G.; Srivastava, D. N.; Palchik, O.; Palchik, V.; Slifkim, M. A.: Weiss, A. M.; Gedanken, A. Langmuir 2002, $18,3352$.

8. Dai, T.; Brulening. M. L.: Nano Left. 2002. 2. 497

9. Manna, A.; Imae, T.; Iida, M; Hisamatsu, N. Langntiv 2001, 17, 6000 .

10. Brust, M:; Walker, M: Bethell, D : Schiffrin, D. T; Whyman, R. J. Chem Soc. Chem Commm 1994. 801

11. Lee, P. C.; Meisel, D. J. Phys, Chem 1982, 86,3391

12. Creighton. J. A.: Blatchford. C. G.: Albrecht. M. G. J. Chem. Soc. Faraday Trans. 1979, 275, 790.

13. Turkevich, J;- Stevenson, P. C.; Hiller, J. Discuss. Faraday Soc. $1951,11,55-75$.

14. Evanoff, Jr., D. D.: Chumanov, G. J. Phys. Chem. B 2004, 108 , 13948.

15. Sondi, I.; Matijević, D. V. E. J. Colloid hterface Sci. 2003, 260 , 75.

16. Velikov, K. P.; Zegeres, G. E.; van Blaaderen, A. Longnuir 2003. 19.1384 
17. Rodriguez-Gattono, G.; Diaz, D.; Rendon, L.; Hentández-Segura, G. O.J. Phys. Chem. B 2002, 106, 2482 .

18. Nickel, U,; Castell, A.; Pöppl, K.: Shirtcliffe, N. Langmuir 2000, 16,9087

19. Leopold, N.: Lendl, B. J. Phr's. Chem. B 2003, 107, 5723.

20. Tan, Y: Dai, X:; Li, Y.: Zhu, D. J.M Mater. Chem. 2003, 13, 1069.

21. He, R: Oian, X: Yin, J: Zhu, Z J. Water Chem, 2002, 12,3783.

22. Chen, D. H.; Huang, Y. W. J. Colloid hnterface Sci. 2002, 255, 299.

23. Nie, S.; Emory, S. R. Science 1997, 275, 1102.

24. Shirtcliffe, N.: Nickel, U.; Schneider, S.J. Colloid hiterface Sci. $1999,211,122$.

25. Van Hyning, D. L.; Zukoski, C. F. Longmuir 1998, 14, 7034.

26. Kashiwagi, Y: Yamamoto, M: Nakamoto, M. J. Collofd Intefface

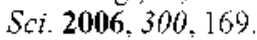

27. Szymaniska, I.; Piszczek, P.: Szczęsny, R.; Szlyk, E. Polyhedron $2007,26,2440$.
28. Lin, X.; Luc, S.: Zhang, T.: Cao, W. Themochimica Acta 2006. $4+10,1$.

29. Monti. O. L. A.; Fourkas, J. T.; Nesbitt, D. I. J. Phus. Chem. B2004. 108,1604 .

30. Singh. N.: Khanna. P. K. Hater. Chent. Phys. 2007, $104,367$.

31. Park, M. S.: Lim, T. H.: Teon, Y. M.: Kim, I. G.: Too, S. W.; Gong, M. S. Macromol Res. 2008, 16, 308

32. Park, M. S.; Lim, T. H.; Teon, Y. M.; Kim, J. G.; Joo, S. W.; Gong, M. S. Sens. Actuators $B$ 2008, 133, 166.

33. Grodzicki, A.: Lakomska, I.: Piszczek, P.: Szymańska, I.; Szłyk, E. Coord. Chem Rev. 2005, 249, 2232

34. Park, M. S.; Lim, T. H.; Teon, Y. M.; Kim, J. G.; Joo, S. W.; Gong, M. S. J. Colloid Interface Sci. 2008, 321,60.

35. Jeon, Y. M.: Cho, H. N.: Gong. M. S. M Aacromol. Res. 2009, 17, 2.

36. Lim, T. H.: Teon, Y. M.: Gong, M. S. Pohmer Korea) 2009, 33 , 33. 